the mechanism whereby the fibrinolytic system may remove deposited fibrin, and a discussion on the relationship between fibrinolysis and occlusive vascular disease. The changes in blood fibrinolytic activity produced by exercise, stress, fat meals, etc., are deseribed. It may be argued that much of the quoted work in this section and, indeed, throughout the book has methodological weaknesses, but there can be little doubt that the use of these methods has contributed to knowledge about fibrinolysis. As the author says, "they are the tools of elinical rather than of fundamental research". There is a persuasive argument for tho use of pharmacological enhancement of blood fibrinolytic activity in the treatment of thromboembolic disease, although evidence of therapeutic efficacy has still to be sought. No such enthusiasm is apparent for the use of thrombolytic therapy, and the author outlines the reasons why such therapy may be of little therapeutic benefit, particularly in occlusion of the coronary and cerebral vessels. There is a suitably brief account of the rare fibrinolytic states which oceur in various pathological conditions. A chapter on the relation. ship between fibrinolysis and coagulation reinforces frequent pleas throughout the book that the two processes should be considered together; their separation into distinct entities loses sight of their probable interplay in a state of dynamic balance. A hint of the protean functions of the fibrinolytic system is provided by a chapter on fibrinolysis and inflammation and a chapter with sections on such topies as its relationship to cancer, renal disease, and immunology. The author finally discusses future developments by pointing out some areas of deficient knowledge and suggesting that their elucida. tion will require the participation of workers of several diseiplines.

This unpretentious monograph is more than a mere aggregation of facts; the author adds a stimulating and sometimes provocative commentary. As befits one who has maintained an active interest in this subject for a decade and a half, he has drawn extensively on his observations. It is pointed out that the investigation of fibrinolysis has become so diverse that it is outside the scope of one individual to be competent and informed on all its aspects. For the non-clinical investigator this monograph will perhaps be disappointing since it is not, nor was it intended to be, a complete reference manual on fibrinolysis. It can, however, be warmly rocommended to the general physician who wishes a readable guide to a relatively new subject. As an introduction to those intending to take up the study of fibrinolysis, it provides a valuable survey of practically every aspect of the subject, and its many suggestions for future research will help to channel effort into productive areas.

D. OGSTON

\section{NEUROTROPHIC PROCESSES}

\section{The Effect of Use and Disuse on Neuromuscular Func- tions}

Edited by Ernest Gutmann and Pavel Hnik. (Proceedings of a Symposium held at Liblice, near Prague, September 18-23, 1962.) Pp. 576. (Amsterdam, London and New York: Elsevier Publishing Company, 1963.) $100 s$.

Mechanisms of Neural Regeneration

Edited by M. Singer and J. P. Schade. (Progross in Brain Research, Vol. 13.) Pp. $v+241$. (Amsterdam, London and New York: Elsevier Publishing Company, 1964.) 80s.

T $T$ has long been known that many organs tend to 1 atrophy when deprived of their nerve supply; this has naturally led to the concept of a trophic influence of nerve fibres, which is thought to be conveyed either by special trophic fibres, or by the ordinary motor and sensory innervation. This kind of influence, whatever its true nature, acts in a very slow and intangible manner, and it was therefore somewhat neglected by experi- mentalists while the more readily distinguishable electrical events accompanying nerve conduction and synaptic transmission were being analysed in great dotail.

In recent years, however, the trophic processes have become of great interest to many biologists; if anyone should doubt this, he need only glance at these two large books. In the first symposium (first book), held in Czechoslovakia, sixty-six participants contributed nearly fifty short articles, covering a groat variety of subjects. They have been classified basically into two main groups. The first covers the trophic function of the nerve cell, as roflected in long-term interactions between nerve and muscle. Here, one finds articles by Eccles, Gutmann, Miledi, Thesleff, Hnik and others, dealing with the properties of denervated and re-innervated muscle; further articles by Eccles, Szentagothai, Buller, otc., describe ehanges in the properties of muscle which follow re-innervation by foreign nerve fibres; and finally there is a discussion of axonal flow by Woiss and by Lubinska, as well as a somewhat less obviously relevant description by Hyden of neurono-glial interactions.

The second main group is concerned with the effects of use and disuse on nerve and musele cells. Most of the observations on nerve cells were made on spinal motoneurones (Asratyian, Eccles, Kostyuk, Beranek, etc.), but three articles by Hyden, Malcolm and Desmedt also describe experiments on cercbral neurones; in the final section, various aspects of muscle function and metabolism are considered by several authors, including Feng, Lissak and Shamarina. This book is full of fascinating information and interesting ideas; as usual, many questions are raised, the most glaring perhaps being that of the identity of the specific trophic factors which are generally assumed to be released by nerve fibres. There is, at present, scarcely any evidence about the kind of substances which are likely to be involved.

Although the second book is part of the now wellestablished series published under the general title of Progress in Brain Research, it is mainly concerned with changes observed in peripheral nerves. The approach here is much more didactic; there are only nine authors and their articles are based on lectures given at a summer school on brain research. Most of these articles are com. prehensive reviews of selected subjects and they include extensive lists of references. Thus, although thero is a substantial overlap with the Czech symposium, both in subject-matter and in authors (five authors are found in both books), the emphasis is mainly on processes of regeneration, and the tone and presentation are quite different.

There are three long reviews, by Lubinska on axoplasmic streaming, by Gutmann on neurotrophic relations and by Zelena on the degeneration and regeneration of receptor organs. Other substantial articles deal with intraxonal movements of phospholipids (Miani), the nerve growth factor and spinal regeneration (Scott and Liu), demyelination and remyelination (Webster) and some other aspects of the mechanism of regeneration (Trampush). Apart from a singularly obscure and unhelpful introduc. tion (by the presumably overworked editors of this prolific series), most of the material has been clearly presented and it should be of much value to anyone needing detailed information in this field.

Both books have been well produced, with very legible print and with plenty of figures and tables, and each has an author index and a subject index; moreover, unlike the Proceedings of many other symposia, they have been published with commendablo speed. Both books roport a good deal of the informal discussions held during the meetings. Most readers will no doubt have their own views about the desirability of this rather general practice; to me, it seldom seems to add much substance to the main presentations, yet it must often contribute appreciably to the bulk and the cost and the delays of publication.

K. KRNJEvić 